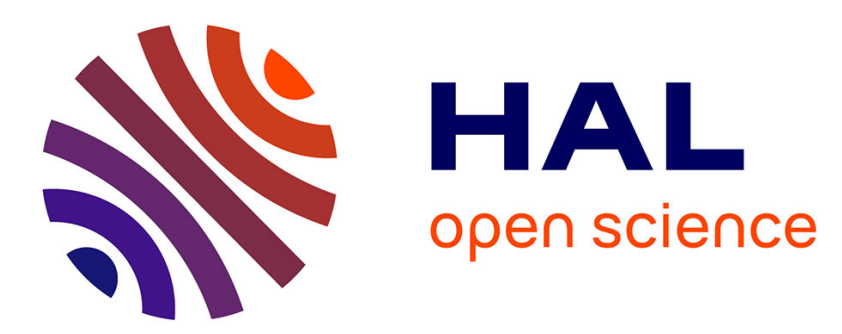

\title{
Process for symbiotic culture of Saccharomyces cerevisiae and Chlorella vulgaris for in situ $\mathrm{CO} 2$ mitigation
}

\author{
Angela La, Patrick Perre, Behnam Taidi
}

\section{- To cite this version:}

Angela La, Patrick Perre, Behnam Taidi. Process for symbiotic culture of Saccharomyces cerevisiae and Chlorella vulgaris for in situ CO2 mitigation. Applied Microbiology and Biotechnology, In press, 10.1007/s00253-018-9506-3 . hal-01959181

\section{HAL Id: hal-01959181 \\ https://hal.science/hal-01959181}

Submitted on 18 Dec 2018

HAL is a multi-disciplinary open access archive for the deposit and dissemination of scientific research documents, whether they are published or not. The documents may come from teaching and research institutions in France or abroad, or from public or private research centers.
L'archive ouverte pluridisciplinaire HAL, est destinée au dépôt et à la diffusion de documents scientifiques de niveau recherche, publiés ou non, émanant des établissements d'enseignement et de recherche français ou étrangers, des laboratoires publics ou privés. 


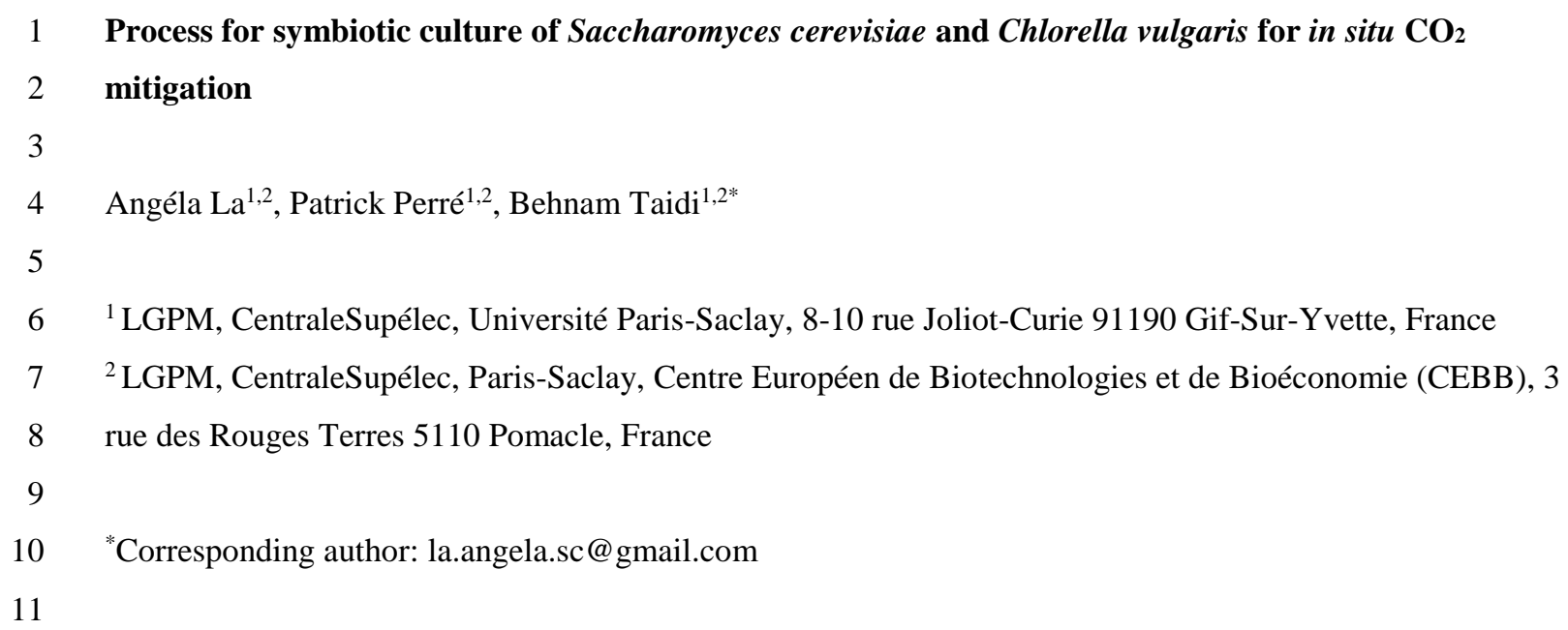

\section{Abstract}

13 Industrial biotechnology relies heavily on fermentation processes that release considerable amounts of $\mathrm{CO}_{2}$.

14 Apart from the fact that this $\mathrm{CO}_{2}$ represents a considerable part of the organic substrate, it has a negative 15 impact on the environment. Microalgae cultures have been suggested as potential means of capturing the $\mathrm{CO}_{2}$ 16 with further applications in high value compounds production or directly for feed applications. We developed 17 a sustainable process based on a mixed co-dominant culture of Saccharomyces cerevisiae and Chlorella 18 vulgaris where the $\mathrm{CO}_{2}$ production and utilization controlled the microbial ecology of the culture. By mixing 19 yeast and microalga in the same culture the $\mathrm{CO}_{2}$ is produced in dissolved form and is available to the 20 microalga avoiding degassing and dissolution phenomena. With this process, the $\mathrm{CO}_{2}$ production and 21 utilization rates were balanced and a mutual symbiosis between the yeast and the microalga was set-up in the 22 culture. In this study the reutilization of $\mathrm{CO}_{2}$ and growth of $C$. vulgaris was demonstrated. The two organism populations were balanced at approximately $20 \times 10^{6}$ cells $\mathrm{ml}^{-1}$ and almost all the $\mathrm{CO}_{2}$ produces by yeast was reutilized by microalga within $168 \mathrm{~h}$ of culture. The $C$. vulgaris inoculum preparation played a key role in establishing co-dominance of the two organisms. Other key factors in establishing symbiosis were the inoculum ratio of the two organisms and the growth medium design. A new method allowed the independent enumeration of each organism in mixed culture. This study could provide a basis for the development of green processes of low environmental impact.

\section{Keywords}




\section{Introduction}

Industrial biotechnology such as bioethanol production, alcoholic beverage production and liquid effluent treatments form a considerable part of human biological activity. These industries, involving fermentation technology, release large quantities of $\mathrm{CO}_{2}$. At the same time, the current trend is towards more sustainable industrial processes. Waste recycling is increasingly seen not only as an obligation but an opportunity in industry.

Commercially, the loss of a considerable part of the substrate in the form of $\mathrm{CO}_{2}$ is an inefficient practice that cannot be avoided with microbial cultures. $\mathrm{CO}_{2}$ mitigation from exhausts gases could provide an opportunity where the substrate would be entirely used at the same time rendering the process sustainable. To this end, photosynthesis is the best candidate to be associated to the normal production process. This is present in nature, often based on symbiotic relationships between organisms, and in some industrial sectors such as sewage treatment.

Biotransformation can be achieved through the use of GMO organisms. Alternatively, biotransformation can be performed by the use of specific consortia to create the desired microbial ecology. The ability to control mixed cultures is key to the use of consortia for biotransformation.

The term "symbiosis" is credited to Heinrich Anton de Bary who first used and described it as "the living together of unlike named organisms" in 1879 (Oulhen et al. 2016). One of the most studied natural composite organisms, considered as the model of symbiosis, is the lichen. Lichen arises from a symbiotic relationship between a fungi and algae or cyanobacteria (Gargas et al. 1995) and the metabolites obtained from lichens have application in industries such as pharmaceutical industry (Müller 2001).

Co-culture systems based on symbiosis between microbial species have been attempted for biotechnological applications in bioprocess and environmental protection (Santos and Reis 2014; Magdouli et al. 2016). The choice of microbial species (microalgae, bacteria or yeast) depends on the final aims of co-culture: harvesting by bioflocculation (Subashchandrabose et al. 2011; Rai et al. 2012), wastewater treatment (Arumugam et al. 2014), production of extracellular polymeric substances (Haggstrom and Dostalek 1981) or growth promotion and lipid production (Milledge and Heaven 2013; Pragya et al. 2013).

Reports of studies on symbiotic co-cultures of microalgae and yeast have been increasingly appearing in the scientific literature, with the aim of improving biomass and target molecule productivity. These co-cultures fall into two categories: studies with bioreactors in series where the exhaust gases from the heterotrophic culture are fed into the autotrophic culture, and studies where both yeast and microalgae are concomitantly in 
the same culture. We have decided to refer to the former as coupled cultures and the latter as mixed cultures (Fig. 1).

Coupled cultures consists of an upstream heterotrophic yeast-culture connected to an autotrophic culture of microalgae in photo-bioreactor through the exhaust gases from yeast culture (Puangbut and Leesing 2012; Santos et al. 2013; Dillschneider et al. 2014; Chagas et al. 2015). Studies on coupled cultures have suggested an increase in the final microalgae biomass and lipid production that is achieved by effectively enriching the air supply to the microalgae cultures with $\mathrm{CO}_{2}$ from the heterotrophic culture. In a coupled-culture system, the autotrophic organism benefits from the heterotrophic organism with no positive or negative impact on the latter, therefore the symbiosis is commensal.

The mixed culture system of microalgae and yeast focuses on the symbiotic potential of associating both organisms in the same culture. This system has an advantage over coupled-cultures in that it provides an opportunity for direct gaseous exchange in dissolved form bypassing the dissolution and degassing rates of the gas supply. Usually, any gas supplied to a bioreactor has to pass from a gaseous phase into a liquid phase (dissolution) and the gases produced by the culture have to pass from the liquid phase into the gaseous phase (degassing). These transfers are subject to specific surface limitations as well as mixing phenomena that can limit $\mathrm{CO}_{2}$ supply for the autotroph and $\mathrm{O}_{2}$ supply for the heterotroph in a coupled culture. In a mixed culture of microalgae and yeast, each organism would use the gas produced by the other organism in situ and without passing through a gaseous phase, the organisms would benefit from each other, so the symbiosis based on these gas exchanges would be mutual.

From a $\mathrm{CO}_{2}$ mitigation viewpoint, as the heterotrophic $\mathrm{CO}_{2}$ production rate is usually largely superior to it autotrophic consumption, the two populations must be balanced in such way so that the photosynthetic population can cope with the rate of $\mathrm{CO}_{2}$ production. Hence the heterotrophic activity must be in step with the $\mathrm{CO}_{2}$ removal rate. This could be achieved though co-dominance of the populations allowing synergy between the two organisms based on gaseous exchange. So far, no scientific studies have been published with the stated aim of developing co-dominant symbiotic mixed cultures.

One of the main challenges for a mixed culture of yeast and microalgae appears to be the dominance of one organism over the other by the end of incubation period. The dominance seems to be due to the use of a culture medium that preferentially promotes either the growth of the yeast or that of microalgae (Dong and Zhao 2004; Cai et al. 2007; Xue et al. 2010; Cheirsilp et al. 2011; Shu et al. 2013; Zhang et al. 2014). In Zhang et al. 2014, a mixed culture of yeast Rhodotorula glutinis and microalga Chlorella vulgaris showed a yeast dominance of $88 \%$ of the total population after 2.5 days of growth $\left(18 \mathrm{~g} \mathrm{l}^{-1}\right.$ of yeast and $2.4 \mathrm{~g} \mathrm{l}^{-1}$ of microalgae). Additionally, the maximum biomass concentration reached by the yeast in monoculture was 8.5 
times higher than of the microalga in monoculture (14.5 and $1.7 \mathrm{~g} \mathrm{l}^{-1}$ respectively), this suggests that the medium designed for mixed culture was more suitable for yeast than microalgae. Inversely in Cai et al.

106 (2007), the microalga Isochrysis galbana was dominant in the mixed culture at the end of the experiment (97

$107 \%$ of the total population). In this study, the medium seems to have been more adapted to the microalgae

108 rather than yeast Ambrosiozyma cicatricose, leading to microalgae dominance. In these studies, on mixed cultures, no mention of the enumeration method in the mixed culture is made.

The present study was conducted to develop a co-dominant and symbiotic mixed culture of two model

112 organisms: the yeast Saccharomyces cerevisiae and the microalga Chlorella vulgaris. In order to promote co-

113 dominance between the two organisms, a new growth medium was specifically designed, and the inoculum

114 ratio was adjusted. The two species were grown in the same medium and in a non-aerated photo-bioreactor

115 fitted with a fermentation lock to prevent gas exchange with the outside atmosphere. The absence of external

116 air supply is intended to force the mutual symbiosis through synergetic effects of in situ gas exchange. To

117 monitor the proportion of populations, a flow cytometric method was used to determine the cell concentration

118 of each population in the mixed-culture. Dissolved $\mathrm{O}_{2}$ and $\mathrm{CO}_{2}$ were continuously measured in-line to

119 evaluate the in situ gas exchange between the two species and to proof the mutual symbiosis.

Through this study, we propose a general methodology for the design of a co-dominant symbiotic mixed culture of a heterotroph and an autotroph in general and assess the success and the challenges of such strategy. The work presented here was performed on well-known model organisms but can provide the basis for more applied studies. The potential advantage of this work is that a symbiotic mixed culture would self-regulate the speed of the bioconversion hence the $\mathrm{CO}_{2}$-production and -utilization rates; it could potentially eliminate the need for gas supply and can lead to full utilization of the substrate. The potential savings would be those of recovering the cost of the portion of the substrate that is normally lost as $\mathrm{CO}_{2}$, making considerable savings in terms of gas supply avoidance and reducing environmental $\mathrm{CO}_{2}$ emissions. In an economical assessment, all these savings would have to be weighed against the losses incurred by moderating the bioconversion speed in step with the photosynthetic rate.

131

\section{2}

\section{Materials and methods}

133

\section{Strategy of this study}

135 A diagram (Fig. 2) demonstrates the strategy used to establish co-dominant culture of S. cerevisiae and $C$.

136 vulgaris. 
Microbial strains and their maintenance

S. cerevisiae strain ID YLR249W was supplied by Life Technologies-University of California San Francisco. This clone expresses a cytoplasm fusion protein coupled to a green fluorescent protein (GFP). The protein of interest is the translation elongation factor 3 encoded by the gene YEF3 (Qin et al. 1987). The strain was maintained on YPG agar stock plates incubated at $25^{\circ} \mathrm{C}$ for 3 days and subsequently stored at $4{ }^{\circ} \mathrm{C}$ for 3 months before subculture. The YPG agar medium was composed of $\left(\mathrm{g} \mathrm{l}^{-1}\right)$ : yeast extract (10), peptone (20) glucose (10) and agar (15) and the stock plates were renewed every three months. C. vulgaris SAG 211-12 was obtained from the Culture Collection of Algae (SAG), University of Göttingen, Germany. The strain was maintained in liquid culture (50 $\mathrm{ml}$ in $250 \mathrm{ml}$ flask) through weekly subculture into fresh medium, incubated at $25^{\circ} \mathrm{C}$ on an orbital shaker $(120 \mathrm{rpm})$ with continuous lighting at $20 \mu \mathrm{mol} \mathrm{m}^{-2} \mathrm{~s}^{-1}$ at the surface of the culture and in air enriched with $1.5 \%(\mathrm{v} / \mathrm{v}) \mathrm{CO}_{2}$. The liquid inorganic medium used was MBM (modified 3N-Bristol medium) (Clément-Larosière et al. 2014), with the following composition (mg l $^{-}$ $\left.{ }^{1}\right): \mathrm{NaNO}_{3}(750) ; \mathrm{CaCl}_{2} .2 \mathrm{H}_{2} \mathrm{O}(25) ; \mathrm{MgSO}_{4} .7 \mathrm{H}_{2} \mathrm{O}$ (75); FeEDTA (20); $\mathrm{K}_{2} \mathrm{HPO}_{4}$ (75); $\mathrm{KH}_{2} \mathrm{PO}_{4}(175) ; \mathrm{NaCl}$ (20); $\mathrm{H}_{3} \mathrm{BO}_{3}$ (2.86); $\mathrm{MnCl}_{2} .4 \mathrm{H}_{2} \mathrm{O}$ (1.81); $\mathrm{ZnSO}_{4} .7 \mathrm{H}_{2} \mathrm{O}(0.22) ; \mathrm{CuSO}_{4} .7 \mathrm{H}_{2} \mathrm{O}$ (0.08); $\mathrm{MoO}_{3} 85 \%$ (0.036); $\mathrm{CoSO}_{4} .7 \mathrm{H}_{2} \mathrm{O},(0.09)$.

153 Monocultures of $S$. cerevisiae and $C$. vulgaris were grown in three different media in order to define a medium suitable for co-dominance of the organisms in mixed culture. The media were based on different combinations of the microalgae growth medium (MBM) (described above) and components from the commonly used yeast growth YPG (yeast extract, peptone and glucose) medium $\left(\mathrm{g} \mathrm{l}^{-1}\right)$ :

- $\quad$ MBM-G: MBM medium with glucose (10)

160 - $\quad$ MBM-GY: MBM medium with glucose (10) and yeast extract (10)

161 - $\quad$ MBM-GP: MBM medium with glucose (10) and peptone (20)

162 Erlenmeyer flasks ( $50 \mathrm{ml}$ working volume; $250 \mathrm{ml}$ total volume) were used for the monoculture of $C$. vulgaris

163 and $S$. cerevisiae in the above media and the inoculation ratio was $1 \%$ (v/v) from a fully-grown culture. The

164 flasks were incubated at $25^{\circ} \mathrm{C}$ on an orbital shaker $(120 \mathrm{rpm})$ with continuous lighting at $80 \mu \mathrm{mol} \mathrm{m}^{-2} \mathrm{~s}^{-1}$

165 (LI250A Light Meter; LI-COR, USA) at the surface of the cultures. Yeast monocultures were conducted for 3 166 days and microalgae monocultures for 5 days.

167 The medium finally selected and specifically designed for the mixed culture was named MBM-GP and was 168 composed of $\left(\mathrm{mg} \mathrm{l}^{-1}\right)$ : $\mathrm{NaNO}_{3}(1,500) ; \mathrm{CaCl}_{2} \cdot 2 \mathrm{H}_{2} \mathrm{O}$ (50); $\mathrm{MgSO}_{4} \cdot 7 \mathrm{H}_{2} \mathrm{O}$ (150); FeEDTA (40); $\mathrm{K}_{2} \mathrm{HPO}_{4}$ (75); $\mathrm{KH}_{2} \mathrm{PO}_{4}(175) ; \mathrm{NaCl}(20) ; \mathrm{H}_{3} \mathrm{BO}_{3}$ (2.86); $\mathrm{MnCl}_{2} .4 \mathrm{H}_{2} \mathrm{O}(1.81) ; \mathrm{ZnSO}_{4} .7 \mathrm{H}_{2} \mathrm{O}(0.220) ; \mathrm{CuSO}_{4} .7 \mathrm{H}_{2} \mathrm{O}(0.08) ;$ $\mathrm{MoO}_{3} 85 \%$ (0.036); $\mathrm{CoSO}_{4} .7 \mathrm{H}_{2} \mathrm{O},(0.09)$, glucose (10,000); peptone (20,000). 


\section{Cultures in photo-bioreactors}

173 All experiments in photo-bioreactor (PBR) were conducted in a stirred bioreactor (5-liter working volume) 174 (BIOSTAT Bplus - 5 L CC; Sartorius Stedim biotech, Göttingen, Germany). The PBR was lit with six LED 175 lamps (Ledare 130 lumen, 2700 Kelvin, $27^{\circ}$ dispersion angle, IKEA, Leiden, Netherlands). The light intensity 176 at the inner surface of the bioreactor for each lamp was measured at 1,600 $\mu \mathrm{mol} \mathrm{m}^{-2} \mathrm{~s}^{-1}$ (LI250A Light Meter; 177 LI-COR, USA). The stirring speed was $750 \mathrm{rpm}$ with a 3-blades pitch-blade impeller (UniVessel 51, 178 Germany), each inclined at $45^{\circ}$ from the horizontal axis. The planar diameter of the impellers was

$17965 \mathrm{~mm}$. The temperature was maintained at $25^{\circ} \mathrm{C}$ and the $\mathrm{pH}$ was controlled at 6.5 with automatic base $\mathrm{KOH}$

$180\left(1 \mathrm{~mol} \mathrm{l}^{-1}\right)$ or acid $\mathrm{H}_{3} \mathrm{PO}_{4}\left(1 \mathrm{~mol} \mathrm{l}^{-1}\right)$ solutions addition based on the continuous measurements made by an 181 internal pH probe (EasyFerm PLUS K8 325, Hamilton, Bonaduz, Switzerland). Dissolved oxygen (pO2) in 182 cultures was measured with an internal probe (VisiFerm DO H2, Hamilton, Bonaduz, Switzerland). The pO2

183 was expressed in terms of $\%$ of $\mathrm{O} 2$ partial pressure in the liquid phase of the culture.

184 The $S$. cerevisiae and $C$. vulgaris specific growth rates $(\mu)$ were calculated as the slope of the linear part of the 185 logarithm of cell concentration plotted versus time.

186

\section{Mixed cultures in PBR}

Two non-aerated mixed cultures in PBR were grown using MBM-GP medium. The experimental set up (Fig. 3) involved hermetically isolating the bioreactor to limit the exchange of gases with the atmosphere at the exterior of the bioreactor.

Dissolved $\mathrm{CO}_{2}\left(\mathrm{pCO}_{2}\right)$ was measured only in the mixed culture No. 1 with an external minisensor integrated in a flow cell (CO2 Flow-Through Cell FTC-CD1, PreSens, Regensburg, Germany). The culture was circulated $\left(90 \mathrm{ml} \mathrm{min}^{-1}\right)$ through the flow cell with the aid of a peristaltic pump (520S/R, Watson Marlow) and back into the bioreactor. The flow-through cell was placed as close to the outlet from the bioreactor as possible. The passage of the culture over the sensor in the flow cell allowed the continuous measurement of $\mathrm{pCO}_{2}$ via an optical fiber. As with the $\mathrm{pO}_{2}$, the $\mathrm{pCO}_{2}$ was expressed in $\%$ of $\mathrm{CO}_{2}$ partial pressure in the liquid phase of the culture.

S. cerevisiae inoculum preparation was the same for both mixed cultures; S. cerevisiae was grown on MBMGP medium, at $25^{\circ} \mathrm{C}$, for 2 days. The preparation of the $C$. vulgaris inocula for the two mixed cultures differed; for the mixed culture No. 1, the $C$. vulgaris inoculum was grown on autotrophic MBM medium under continuous illumination, for 15 days, at $25^{\circ} \mathrm{C}$ and for mixed culture No. 2 the C. vulgaris inoculum was grown on heterotrophic MBM-GP medium under continuous lighting, for 15 days, at $25^{\circ} \mathrm{C}$.

\section{Monoculture of S. cerevisiae in PBR}

The monoculture of $S$. cerevisiae was grown in a non-aerated PBR in MBM-GP medium, with culture parameters as described above and the photo-bioreactor configuration was the same as for mixed culture (Fig. 
3), there was no aeration and gas outlet was closed as described with a fermentation lock. The culture was lit as for mixed culture. The $S$. cerevisiae inoculum was grown in MBM-GP medium, at $25^{\circ} \mathrm{C}$, for 2 days.

\section{Monocultures of $C$. vulgaris in PBR}

Two monocultures of $C$. vulgaris in PBR were grown, one in heterotrophic MBM-GP medium and the other in autotrophic MBM medium. For the first one the inoculum was prepared in MBM-GP medium, the second one using MBM medium and both under continuous light at $25^{\circ} \mathrm{C}$ for 15 days. Both culture conditions were set up as described above and the photo-bioreactor was continuously aerated with sterile air (Midisart 2000 $0.2 \mu \mathrm{m}$ PTFE, Sartorius, Göttingen, Germany) at $500 \mathrm{ml} \mathrm{min}^{-1}(0.1 \mathrm{vvm})\left(1 \mathrm{~atm}, 25^{\circ} \mathrm{C}\right)$.

\section{The impact of ethanol on C. vulgaris growth}

C. vulgaris was grown on MBM medium in Erlenmeyer flasks (50 ml working volume; $250 \mathrm{ml}$ total volume) and the flasks were incubated at $25^{\circ} \mathrm{C}$ on an orbital shaker $\left(120 \mathrm{rpm}\right.$ ) with continuous lighting at $20 \mu \mathrm{mol} \mathrm{m}^{-2}$ $\mathrm{s}^{-1}$ and in air enriched with $\mathrm{CO}_{2} 1.5 \%(\mathrm{v} / \mathrm{v})$. Four ethanol concentrations were tested $\left(0,2,4\right.$ and $\left.6 \mathrm{~g} \mathrm{l}^{-1}\right)$ (ethanol $96 \%$ ).

\section{Analytical methods}

\section{Simultaneous enumeration of $C$. vulgaris and $S$. cerevisiae by flow cytometry}

A flow cytometer (Guava easyCyte ${ }^{\mathrm{TM}}$, EMD Millipore, Burlington, United States) was used to simultaneously determine the cell concentrations of $S$. cerevisiae and $C$. vulgaris in mixed culture. The excitation wavelength of the blue laser was $488 \mathrm{~nm}$ and detectors separately captured the Forward-scattered light (FSC) that is proportional to cell-surface area (size), the Side-scattered light (SSC) that indicated particles granularity and the fluorescence emitted by the cell (auto-fluorescence). Samples were diluted so that the cell enumeration

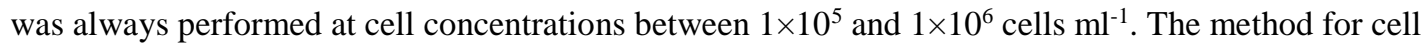
enumeration by flow cytometer suspensions containing only one of the microorganisms was previously validated against a Thoma counting chamber as the referent method (data not shown). Cell viability of $C$. vulgaris was also determined by flow cytometry using the Guava ViaCount Reagent (EMD Millipore, Burlington, United States).

\section{Glucose and ethanol measurements}

Culture supernatants were prepared by sample centrifugation (10 min, $3500 \mathrm{~g}$ ), filtration (PTFE Syringe Filter $0.2 \mu \mathrm{m}$, Fisherbrand, Waltham, United Stated) and High Pressure Liquid Chromatography (HPLC) (Ultimate 3000, Thermo Scientific, United States). A cationic column (Aminex HPX-87H, Bio-Rad, United States) was used with $2 \mathrm{mM}$ sulfuric acid as the mobile phase with a flow rate of $0.5 \mathrm{ml} \mathrm{min}^{-1}$, an injection volume of 10 
$\mu 1$, a temperature of $45^{\circ} \mathrm{C}$ and a pressure of 60 bar. Detection was by means of a refractive index (RI) detector (RI 101, Shodex, Japan).

\section{Dry weight}

The dry weight was determined by sampling and centrifuging $10 \mathrm{ml}$ of culture (10 min and 1,800 g). The pellet was washed with an equal volume of deionized water, and was centrifuged again (10 min, $1800 \mathrm{~g}$ ) and the final pellet was transferred into a dry pre-weight ceramic cup $\left(24 \mathrm{~h}, 105^{\circ} \mathrm{C}\right)$. The pellet was dried overnight at $105^{\circ} \mathrm{C}$ and cooled in a desiccator containing dry silica gel prior to weighing. A correlation between the dry weight and the cell concentration was established for $S$. cerevisiae and C. vulgaris: $\mathrm{DW}_{\text {yeast }}=$ $3.25 \times 10^{-8} \mathrm{~N}_{\text {yeast }}\left(9\right.$ data points and $\left.\mathrm{R}^{2}=0.91\right)$ and $\mathrm{DW}_{\text {algae }}=1.5 \times 10^{-8} \mathrm{~N}_{\text {algae }}\left(13\right.$ data points and $\left.\mathrm{R}^{2}=0.96\right)$ with DW the dry weight $\left(\mathrm{g} \mathrm{l}^{-1}\right)$ and $\mathrm{N}$ the cell concentration (cells ml${ }^{-1}$ ). The experimental data points for the yeast were obtained from a monoculture in PBR using the MBM-GP medium and for the microalgae from a monoculture in PBR using the autotrophic medium MBM.

\section{Results}

\section{$\mathrm{CO}_{2}$ production and consumption}

$\mathrm{CO}_{2}$ produced by yeast was assumed to be the main cause of culture acidification, resulting in the automatic addition of base $(\mathrm{KOH})$ under the experimental conditions designed to keep the $\mathrm{pH}$ at 6.5. Consequently, the quantity of $\mathrm{KOH}$ solution is directly proportional to the $\mathrm{CO}_{2}$ produced and was used to estimate the amount of $\mathrm{CO}_{2}$ produced by yeast. The difference in the $\mathrm{KOH}$ added into the yeast monoculture and the mixed culture indicated the amount of $\mathrm{CO}_{2}$ used by $C$. vulgaris and was used to perform a carbon mass balance.

\section{Resuits}

Validation of simultaneous enumeration of $C$. vulgaris and $S$. cerevisiae by flow cytometry A method for separately-enumerating C. vulgaris and S. cerevisiae populations in a mixed suspension was developed. The two species were distinguished on the basis of their specific auto-fluorescence detected by flow cytometry. $C$. vulgaris cells were distinguished through chlorophyll fluorescence (emission wavelength of $650 \mathrm{~nm}$ ) and S. cerevisiae with the fluorescence of the constitutively expressed GFP protein (emission wavelength of $525 \mathrm{~nm}$ ) (Fig. S1).

To validate the method, eleven mixed suspensions were prepared over a range of precise microalgae:yeast ratios (reference ratios) and the two populations in the mixed suspensions were measured with flow cytometry (experimental ratios). By plotting the experimental $C$. vulgaris ratio as a function of the referent microalgae ratio (Fig. 4), a linear relationship was obtained with a slope of 1.048 (correlation coefficient of 0.997 ; 11 data points). A linear relationship was also found for S. cerevisiae with a slope of 0.996 and a correlation coefficient of 0.998 , validating the method for enumerating microalgae and yeast simultaneously in mixed suspensions. 


\section{Strategy for a co-dominance of $C$. vulgaris and $S$. cerevisiae in mixed culture}

\section{Design of a specific medium for mixed culture}

A growth medium that allowed the growth of both organisms was necessary. According to Fig. 5, MBM-G medium allowed only microalgae growth and $S$. cerevisiae growth was barely detectable. Monocultures of $C$. vulgaris and S. cerevisiae in MBM-GY medium showed the opposite results from those in MBM-G medium: MBM-GY allowed good growth of S. cerevisiae but not of C. vulgaris.

In MBM-GP medium, both $C$. vulgaris and $S$. cerevisiae could grow: the maximum $C$. vulgaris population was $2 \times 10^{8}$ cells ml ${ }^{-1}$ and the maximum yeast population was 10 times lower $\left(2 \times 10^{7}\right.$ cells ml $\left.{ }^{-1}\right)$.

\section{Definition of parameters for mixed culture in PBR}

The temperature and $\mathrm{pH}$ in PBR were chosen to favor C. vulgaris growth. According to Kumar et al. (2010), temperatures of $15-26^{\circ} \mathrm{C}$ and neutral $\mathrm{pH}$ is optimal for microalgae growth. The form of the dissolved $\mathrm{CO}_{2}$ concentration and the $\mathrm{pH}$ of the culture are directly linked so we chose to control the $\mathrm{pH}$ at 6.5 to achieve a good compromise between having a neutral $\mathrm{pH}$ and the dissolved $\mathrm{CO}_{2}$ and bicarbonate species proportioned at around 0.5 at $25^{\circ} \mathrm{C}$ (Edwards et al. 1978).

The inoculum ratio was set up in way to minimize dominance of yeast and favor microalgae growth:

$$
\mathrm{X}_{0 \text { C. vulgaris }}=\frac{\mathrm{X}_{0 \text { S. cerevisiae }} \mathrm{e}^{\mu_{\text {s. cerevisiae }} \mathrm{t}}}{\mathrm{e}^{\mu \text { c. vulgaris } \mathrm{t}}}
$$

with:

$\mathrm{X}_{0}$ C. vulgaris: initial C. vulgaris population

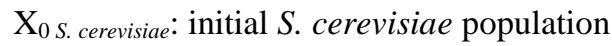

$\mu_{\text {S. cerevisiae: }}$ S. cerevisiae specific growth rate

$\mu_{\text {C. vulgaris: }}$ C. vulgaris specific growth rate

t: duration of the S. cerevisiae exponential phase.

\section{Monocultures in PBR}

Yeast and microalgae monocultures in PBR served as reference cultures for mixed culture. In the case of $C$. vulgaris, two reference conditions were tested: heterotrophic growth in the presence of glucose and, autotrophic growth in the absence of glucose. The behavior of the individual species in mixed cultures would then be compared to the latter reference conditions. 
312 S. cerevisiae was grown on MBM-GP medium in PBR without aeration, exactly under the same conditions as for the subsequent mixed culture.

The yeast exponential growth phase $\left(\mu=0.27 \mathrm{~h}^{-1}\right)$ occurred within the first $24 \mathrm{~h}$ of incubation $(15 \mathrm{~h}$ of exponential phase) and was accompanied with glucose and $\mathrm{O}_{2}$ consumption. S. cerevisiae used all glucose within the first $31 \mathrm{~h}$ of incubation reaching a maximum population of $2.2 \times 10^{7}$ cells $\mathrm{ml}^{-1}$ (Fig. 6). Within the first $31 \mathrm{~h}$, S. cerevisiae also produced ethanol to a peak concentration of $4 \mathrm{~g}^{-1}$.

\section{Monocultures of $C$. vulgaris in aerated PBR in mixotrophic conditions}

C. vulgaris was grown on MBM-GP medium in PBR in the same way as S. cerevisiae in monoculture and as mixed cultures except that the $C$. vulgaris monocultures were continuously aerated. Aeration was mandatory for $\mathrm{CO}_{2}$ provision to $C$. vulgaris for photosynthesis. $\mathrm{The}^{\mathrm{pO}}$ in the culture was expected to be stable at 20.9 $\%$ in the absence of net production or consumption of $\mathrm{O}_{2}$ by C. vulgaris.

During the first $48 \mathrm{~h}$ of $C$. vulgaris growth in MBM-GP (Fig. 7a), the glucose and $\mathrm{O}_{2}$ concentrations did not decrease while the population increased slightly from $1 \times 10^{6}$ to $1.8 \times 10^{6}$ cells ml-1. From 48 to $116 \mathrm{~h}$ of incubation, glucose decreased to complete depletion while the microalgae population increased from $1.8 \times 10^{6}$ to $4 \times 10^{8}$ cells $\mathrm{ml}^{-1}$. During this period, the presumed heterotrophic microalgae growth was exponential with $\left.\mu=0.09 \mathrm{~h}^{-1}\right)$.

\section{Monocultures of $C$. vulgaris in aerated PBR in photo-autotrophic conditions}

C. vulgaris was grown in autotrophic monoculture using MBM medium in the absence of glucose (photoautotrophically) and with continuous aeration (Fig. 7b) to supply atmospheric $\mathrm{CO}_{2}$ as carbon source. The microalgae firstly grew exponentially $\left(\mu=0.02 \mathrm{~h}^{-1}\right)$, increasing the population from $9 \times 10^{5}$ to $2 \times 10^{7}$ cells $\mathrm{ml}^{-1}$ and producing $\mathrm{O}_{2}$ via photosynthesis. Starting from a value of $21 \%$, the $\mathrm{pO}_{2}$ reached $22 \%$ at the end of the exponential growth phase $(100 \mathrm{~h})$ then it continued to increase up to $22.3 \%$ and remained constant at the same level. This is a significant level of $\mathrm{O}_{2}$ production considering the continuous flow of the air through the photobioreactor and the concentration of cells in the culture.

\section{Impact of ethanol on $C$. vulgaris growth}

The impact of the ethanol produced by S. cerevisiae when grown in MBM-GP medium in photo-bioreactor culture was assessed on $C$. vulgaris growth. Ethanol was added to $C$. vulgaris shake-flask cultures when the population reached $7 \times 10^{6} \mathrm{cells} \mathrm{ml}^{-1}$ (corresponding to the initial C. vulgaris population in the mixed culture). Four ethanol concentrations $\left(2,4,6 \mathrm{~g} \mathrm{l}^{-1}\right.$ and $\left.0 \mathrm{~g} \mathrm{l}^{-1}\right)$ were chosen according to the range of ethanol concentrations that could be produced by $S$. cerevisiae in monoculture and mixed culture (Fig. S2). The $C$. vulgaris growth profile was the same in all cultures (with or without the addition of ethanol). Moreover, cell viability of the four cultures remained at approximately $98 \%$. 


\section{Mixed culture No. 1}

In the first mixed culture, the yeast inoculum was prepared in the newly designed MBM-GP medium while

352 the microalgae inoculum was prepared in autotrophic MBM medium.

353 The S. cerevisiae behavior was similar in both mixed culture No. 1 (Fig. 8) and in the reference yeast monoculture (Fig. 6) (same maximum population, same specific growth rate, and same ethanol productivity). On the other hand, the $C$. vulgaris growth in mixed culture No. 1 was weak compared with the reference photoautotrophic mixed culture. The microalgae population only slightly increased from $7 \times 10^{6}$ to $9 \times 10^{6}$ cells $\mathrm{ml}^{-1}$ within the first $13 \mathrm{~h}$ and remained mainly constant until the end of incubation (168 h) but the dissolved $\mathrm{CO}_{2}$ concentration gradually decreased from $16 \%$ to $0 \%$ from $48 \mathrm{~h}$ to $168 \mathrm{~h}$ at the end of the experiment.

\section{Mixed culture No. 2}

For this second mixed culture, both the yeast and the microalgae inocula were prepared in the MBM-GP

362 medium. This was in contrast to the mixed culture No. 1 where the microalgae inoculum was prepared in autotrophic MBM medium. The mixed cultures No. 2 and No. 1 only differed in the microalgae inoculum preparation. All other conditions including the microalgae:yeast inoculum ratio were identical.

The S. cerevisiae behavior was similar in both mixed cultures (Fig. 9) and in the reference yeast monoculture (Fig. 6) in terms of maximum population, specific growth rate, and ethanol productivity. reached a maximum population of $2.4 \times 10^{7}$ cells $\mathrm{ml}^{-1}$, then its population remained stable until the end of the experiment.

\section{$\mathrm{CO}_{2}$ production by $\mathrm{S}$. cerevisiae in monoculture}

In monoculture of $S$. cerevisiae using MBM-GP medium, yeast biomass, ethanol and $\mathrm{CO}_{2}$ were produced during growth, the latter resulting in the acidification of the culture medium. Since a stable $\mathrm{pH}$ was specified

The $\mathrm{CO}_{2}$ released into the culture medium reacts with water to form carbonic acid $\mathrm{H}_{2} \mathrm{CO}_{3}$ and then dissociates into $\mathrm{H}^{+}$and $\mathrm{HCO}_{3}{ }^{-}$(Peña et al. 2015) acidifying the culture medium. Under the $\mathrm{pH}$-control regime, the $\mathrm{KOH}$ 
solution is added to maintain the $\mathrm{pH}$ at 6.5 . The stoichiometry of the reaction between $\mathrm{CO}_{2}$ and $\mathrm{KOH}$ is $1: 1$. A total $\mathrm{KOH}$ volume of $337 \mathrm{ml}$ was added during the yeast growth phase, which corresponded to 0.337 mole of $\mathrm{KOH}$ added to the 5-liter culture medium. For ease of the mass balance calculation, the amount of $\mathrm{KOH}$ added was expressed as a concentration $\left(6.74 \times 10^{-2} \mathrm{~mol} \mathrm{l}^{-1}\right)$ :

$$
[\mathrm{KOH}]=\frac{\mathrm{V}_{\mathrm{KOH}} \times \mathrm{C}_{\mathrm{KOH}}}{\mathrm{V}}
$$

with:

$[\mathrm{KOH}]$ : base $\mathrm{KOH}$ concentration in the culture medium $\left(\mathrm{mol} \mathrm{1}^{-1}\right)$

$\mathrm{V}_{\mathrm{KOH}}$ : volume of $\mathrm{KOH}$ added to the culture medium (l)

$\mathrm{C}_{\mathrm{KOH}}$ : concentration of the $\mathrm{KOH}$ solution added to the photo-bioreactor $\left(\mathrm{mol} \mathrm{l}^{-1}\right)$

V: working volume (5 l)

Assuming that the $\mathrm{KOH}$ reacted exclusively with the $\mathrm{H}^{+}$from the hydration of the $\mathrm{CO}_{2}$ produced, $6.74 \times 10^{-2}$ mol $\mathrm{l}^{-1}$ of $\mathrm{KOH}$ was used for $\mathrm{pH}$ adjustment:

$$
\mathrm{CO}_{2}+\mathrm{H}_{2} \mathrm{O} \rightarrow \mathrm{H}_{2} \mathrm{CO}_{3} \rightarrow \mathrm{H}^{+}+\mathrm{HCO}_{3}^{-}
$$

The $\mathrm{CO}_{2}$ concentration produced by yeast and neutralized by the $\mathrm{KOH}$ was $2.97 \mathrm{~g}^{-1}$ and was calculated as:

$$
\left[\mathrm{CO}_{2}\right]_{\mathrm{KOH}}=[\mathrm{KOH}] \times \mathrm{M}_{\mathrm{CO} 2}
$$

with:

$\left[\mathrm{CO}_{2}\right]_{\mathrm{Kон}}$ : concentration of $\mathrm{CO}_{2}$ produced by yeast and reacted with $\mathrm{KOH}\left(\mathrm{g} \mathrm{l}^{-1}\right)$

$[\mathrm{KOH}]$ : base $\mathrm{KOH}$ concentration in the culture medium $\left(\mathrm{mol} \mathrm{l}^{-1}\right)$

Mc02: molar mass of $\mathrm{CO}_{2}\left(44 \mathrm{~g} \mathrm{~mol}^{-1}\right)$

From the above calculation, $3.91 \mathrm{~g} \mathrm{l}^{-1}$ of $\mathrm{CO}_{2}$ would have been produced during yeast monoculture but only $2.97 \mathrm{~g} \mathrm{l}^{-1}$ of $\mathrm{CO}_{2}$ was measured based on the $\mathrm{KOH}$ used. This means that $0.94 \mathrm{~g} \mathrm{l}^{-1}$ of $\mathrm{CO}_{2}$ remained in solution and/or passed into gaseous phase (Fig. 10b).

\section{$\mathrm{CO}_{2}$ mass balance for $S$. cerevisiae and $C$. vulgaris in mixed culture No. 2}

The $\mathrm{CO}_{2}$ production and biofixation was studied only in mixed culture No. 2 since the dominance between microalgae and yeast was reached in this mixed culture and not in mixed culture No. 1.

In mixed culture No. 2, the $\mathrm{KOH}$ solution was added during the first $39 \mathrm{~h}$ of culture corresponding to yeast growth. As explained above, the S. cerevisiae behavior was similar in both mixed culture No. 2 and in the 
reference yeast monoculture (Fig. 10a); again the assumption was made that the $\mathrm{KOH}$ solution was mainly added to the mixed culture No. 2 to compensate for the medium acidification by the $\mathrm{CO}_{2}$ release by the yeast. $\mathrm{KOH}(283 \mathrm{ml})$ was added during the growth phase of the yeast corresponding to $5.7 \times 10^{-2} \mathrm{~mol} \mathrm{l}^{-1}$ of $\mathrm{CO}_{2}$ equivalent to $2.49 \mathrm{~g} \mathrm{l}^{-1}$ of $\mathrm{CO}_{2}$ (equation 3 and 5).

In the yeast reference monoculture $2.97 \mathrm{~g} \mathrm{l}^{-1}$ of $\mathrm{CO}_{2}$ reacted with $\mathrm{KOH}$ whereas in mixed culture No. 2 only $2.49 \mathrm{~g} \mathrm{l}^{-1}$, of $\mathrm{CO}_{2}$ reacted with $\mathrm{KOH}$. The difference in $\mathrm{CO}_{2}$ concentration most likely corresponds to the amount of $\mathrm{CO}_{2}$ assimilated by microalgae in the mixed culture: $0.48 \mathrm{~g} \mathrm{l}^{-1}$ of $^{\mathrm{CO}_{2}}$ i.e. $0.13 \mathrm{~g} \mathrm{l}^{-1}$ of carbon. This concentration of carbon is coherent with the concentration of carbon required for the $C$. vulgaris biomass measured in mixed culture No. $2 ; 1.5 \times 10^{7}$ cells ml $^{-1}$ of $C$. vulgaris was produced corresponding to a dry weight of $0.23 \mathrm{~g} \mathrm{l}^{-1}$ or $8.8 \times 10^{-3} \mathrm{~mol} \mathrm{l}^{-1}$ (the microalgae composition is $\mathrm{C}_{1} \mathrm{H}_{1.78} \mathrm{~N}_{0.165} \mathrm{O}_{0.495}$ according to Scherholz and Curtis, 2013), and consequently $0.11 \mathrm{~g} \mathrm{l}^{-1}$ of carbon was required for the microalgae biomass production. Hence, the amount of carbon fixed by microalgae was determined by two different methods; the

\section{Discussion}

434 The aim of this work was to establish a symbiotic relationship between a heterotroph organism and an autotroph organism based on gaseous $\left(\mathrm{CO}_{2}\right)$ exchange. For this relationship to be useful in terms of in situ $\mathrm{CO}_{2}$ mitigation, the rates for $\mathrm{CO}_{2}$ production and consumption must be equal and in order to achieve this neither organisms must dominate, hence a co-dominant culture is necessary. medium that would allow the co-dominance of the two species. As the $\mu$ of $C$. vulgaris is considerably smaller (slower) than that of $S$. cerevisiae, the growth medium was designed to favor $C$. vulgaris development and to limit $S$. cerevisiae growth. The MBM-GP medium was a good compromise for a co-dominant culture of C. vulgaris and S. cerevisiae (Fig. 5). Both organisms were able to grow in this medium based on the available nitrogen and carbon for both $C$. vulgaris and S. cerevisiae: $C$. vulgaris could obtain nitrogen from nitrate, both organisms could access the short peptides and amino acids in the peptone and S. cerevisiae could additionally use the $\mathrm{NH}_{3}$ supplied by the peptone. Glucose as carbon source would be available to both organisms but $\mathrm{CO}_{2}$ would be additionally available to $C$. vulgaris. S. cerevisiae growth was limited by the availability of assimilable nitrogen to this organism. S. cerevisiae did not grow in the absence of peptone, as was the case with MBM-G medium. The addition of yeast extract to MBM-G medium to give MBM-GY medium provided a nitrogen source as well as other nutrients that could be used by the yeast for growth, however, the addition of yeast extract to the growth medium proved toxic to C. vulgaris. Finally, the MBMlimiting the maximum yeast population at $10 \%$ of the microalgae population. 
454 Having designed a medium suitable for the growth of both organisms, three reference cultures were grown in

455 photo-bioreactor: a fermentative culture of $S$. cerevisiae without aeration (MBM-GP medium), a culture of $C$.

456 vulgaris under mixotrophic conditions with continuous aeration (MBM-GP medium) and an autotrophic

457 culture of $C$. vulgaris with continuous aeration and in the absence of glucose (MBM medium). Two mixed

458 cultures were also grown without aeration in MBM-GP medium.

459

460

461

462

463

464

465

466

467

468

469

470

471

472

473

474

475

476

477

478

479

480

481

482 For the C. vulgaris photoautotrophic monoculture the exponential growth phase was followed by a longer

483 linear growth phase from the point where the population density increased beyond $2 \times 10^{7} \mathrm{cells} \mathrm{ml}^{-1}$. This is

484 most likely due to light limitation; once the culture reaches a certain population density that would result in

485 considerable autoshadowing and restricted light penetration into the core of the culture. The growth would

486 then be directly related to the light arrival rate, which is constant resulting in linear growth.

487 
In summary, the $S$. cerevisiae monoculture (Fig. 6) and the microalgae $C$. vulgaris autotrophic monoculture (Fig. 7b) were used as reference cultures to compare with the mixed cultures. The respective $\mu$ were used to adjust the microalgae:yeast inoculation ratio to 30:1 (equation 1) in an attempt to minimize the possibility of yeast domination in the mixed culture. Two mixed cultures were grown without aeration where an attempt was made to coordinate the growth of the two organisms by adjusting their respective inoculation rates as described above.

In the first mixed culture (No. 1) (Fig. 8), S. cerevisiae consumed the glucose within the first $48 \mathrm{~h}$ as had been observed in the reference yeast monoculture (Fig. 6). The $S$. cerevisiae biomass and ethanol production were the same for both the mixed culture and the yeast reference culture. Since no glucose was available for the microalgae, $C$. vulgaris probably grew fully photosynthetically in the mixed culture. This was additionally supported by the observation that in the $C$. vulgaris monoculture in the presence of glucose, the glucose was not consumed during the first $48 \mathrm{~h}$ (Fig. 7a). On the other hand, C. vulgaris growth in mixed culture was weak with the maximal microalgae population 2.5 times lower than the reference monoculture $\left(9 \times 10^{6}\right.$ and $2 \times 10^{7}$ cells $\mathrm{ml}^{-1}$ respectively) (Fig. 7b). Ethanol or $\mathrm{CO}_{2}$ toxicity can both be excluded as reasons for this low microalgal biomass production, as discussed below. Although the $C$. vulgaris population was weak, the microalgal cells remained active during the entire experiment $(168 \mathrm{~h})$. During the latter phases of the experiment, there were instances where the sun shone directly on the PBR; intermittent negative $\mathrm{pCO}_{2}$ troughs and concomitant positive $\mathrm{pO}_{2}$ peaks were observed during these transient periods. This can be taken as a strong indicator that both organisms in the mixed culture were metabolically active and that synergy effects between yeast and microalgae occurred. The final $\mathrm{pCO}_{2}$ concentration reached almost its initial level indicating that in principle, in situ $\mathrm{CO}_{2}$ mitigation in mixed culture is feasible, although the efficiency of the

512 A second mixed culture (No. 2) was grown to increase the microalga population in mixed culture (Fig. 9). The

513 C. vulgaris inoculum was prepared in the same medium as used for the mixed culture (MBM-GP) in order to

514 pre-adapt the organism to this medium and promote immediate growth of $C$. vulgaris straight after inoculation

515 into the photo-bioreactor. C. vulgaris grew straight away from the start reaching a maximum population 2.7

516 times higher than that of the first mixed culture. By modifying the preparation of the inoculum, it was

517 possible to achieve the same population concentration for both organisms $\left(2 \times 10^{7}\right.$ cells $\left.\mathrm{ml}^{-1}\right)$. Presumably the

518 pre-adaptation allowed $C$. vulgaris to have the enzymes necessary for the utilization of the amino acids and

519 the small peptides present in the peptone in the photo-bioreactor medium. Like in the first mixed culture, $C$.

520 vulgaris grew on the $\mathrm{CO}_{2}$ produced by $S$. cerevisiae as there was no other source of $\mathrm{CO}_{2}$. Of the $\mathrm{CO}_{2}$

521 produced by S. cerevisiae in mixed culture No. 2, $12 \%$ was consumed directly by C. vulgaris, and the $64 \%$ of

$522 \mathrm{CO}_{2}$ captured by the $\mathrm{KOH}$ was in the $\mathrm{HCO}_{3}{ }^{-}$form and still available to the microalgae for utilization (Fig. $52310 \mathrm{c})$. 
Ethanol is known to exhibit antimicrobial activity by attacking cell membranes (Patra et al. 2006) and it was important to assess the potential toxicity of the ethanol produced by $S$. cerevisiae in mixed culture on $C$. vulgaris. Firstly, the growth of the microalgae in the mixed culture No.2 provided the first indication that at 4 $\mathrm{g} \mathrm{l}^{-1}$, ethanol was not toxic to $C$. vulgaris. This observation was further confirmed with a shake-flask experiment were exogenous ethanol $\left(2,4\right.$ and $\left.6 \mathrm{~g} \mathrm{l}^{-1}\right)$ was added to growing autotrophic cultures of $C$. vulgaris. The same growth profiles were observed for both control cultures and cultures containing ethanol, even at concentrations higher than those measured in mixed cultures. The cell viabilities of these monocultures were high (approx. 100\%) even at the end of the incubation period (411 h).

In conclusion, in order to encourage mutual symbiosis, we developed a mixed culture of $C$. vulgaris and $S$. cerevisiae in PBR in a way that neither organism dominated the other in terms of population concentration. The method developed for simultaneous cell enumeration with flow cytometry permitted to rigorously monitor the two populations in the mixed culture. The dissolved $\mathrm{O}_{2}$ and $\mathrm{CO}_{2}$ probes brought relevant

538 measurements that allowed us to follow gas evolution. The results indicated that the medium design, the

539 culture conditions, the inoculum ratio and the $C$. vulgaris inoculum preparation all contributed for co-

540 dominance of the two species. By comparing the physiological behavior of microalgae and yeast in

541 monoculture and mixed culture, co-dominance and a mutual symbiosis based on in situ gas exchange were

542 demonstrated. This work opens the perspective for in situ $\mathrm{CO}_{2}$ mitigation, full utilization of the organic

543 substrate and a reduction in aeration costs of biotransformation processes.

\section{Acknowledgements}

546 The authors would like to thank Département de la Marne, Région Grand Est, and Grand Reims for their

547 financial support.

\section{Compliance with ethical standards}

550

552 The authors declare no conflict of interest.

558 The authors declare their agreement to authorship and submission of the manuscript for peer review. 


\section{References}

561

Arumugam A, Sandhya M, Ponnusami V (2014) Biohydrogen and polyhydroxyalkanoate co-production by Enterobacter aerogenes and Rhodobacter sphaeroides from Calophyllum inophyllum oil cake. Bioresour Technol 164:170-176 . doi: 10.1016/j.biortech.2014.04.104

Ben Amor-Ben Ayed H, Taidi B, Ayadi H, Pareau D, Stambouli M (2017) The Use of Chlorella vulgaris to Accumulate Magnesium under Different Culture Conditions. J Appl Biotechnol Bioeng 2:180-185

Cai S, Hu C, Du S (2007) Comparisons of growth and biochemical composition between mixed culture of alga and yeast and monocultures. J Biosci Bioeng 104:391-397 . doi: 10.1263/jbb.104.391

Chagas AL, Rios AO, Jarenkow A, Marcílio NR, Ayub MAZ, Rech R (2015) Production of carotenoids and lipids by Dunaliella tertiolecta using $\mathrm{CO}_{2}$ from beer fermentation. Process Biochem 50:981-988 . doi: 10.1016/j.procbio.2015.03.012

Cheirsilp B, Suwannarat W, Niyomdecha R (2011) Mixed culture of oleaginous yeast Rhodotorula glutinis and microalga Chlorella vulgaris for lipid production from industrial wastes and its use as biodiesel feedstock. N Biotechnol 28:362-368 . doi: 10.1016/j.nbt.2011.01.004

Clément-Larosière B, Lopes F, Taidi B, Benedetti M, Minier M, Pareau D (2014) Carbon dioxide biofixation by Chlorella vulgaris at different $\mathrm{CO}_{2}$ concentrations and light intensities. Eng Life Sci 14: . doi: https://doi.org/10.1002/elsc.201200212

Dillschneider R, Schulze I, Neumann A, Posten C, Syldatk C (2014) Combination of algae and yeast fermentation for an integrated process to produce single cell oils. Appl Microbiol Biotechnol 98:77937802 . doi: 10.1007/s00253-014-5867-4

Dong QL, Zhao XM (2004) In situ carbon dioxide fixation in the process of natural astaxanthin production by a mixed culture of Haematococcus pluvialis and Phaffia rhodozyma. Catal Today 98:537-544 . doi: 10.1016/j.cattod.2004.09.052

Edwards TJ, Maurer G, Newman J, Prausnitz JM (1978) Vapor-liquid equilibria in multicomponent aqueous solutions of volatile weak electrolytes. AIChE J 24:966-976 . doi: 10.1002/aic.690240605

Gargas A, DePriest PT, Grube M, Tehler A (1995) Multiple origins of lichen symbioses in fungi suggested by SSU rDNA phylogeny. Science (80- ) 268:1492-1495

Haggstrom MH, Dostalek M (1981) Regulation of a mixed culture of Streptococcus lactis and Saccharomycopsis fibuliger. Eur J Appl Microbiol Biotechnol 12:216-219 . doi: 10.1007/BF00499490

Kumar A, Ergas S, Yuan X, Sahu A, Zhang Q, Dewulf J, Malcata FX, van Langenhove H (2010) Enhanced $\mathrm{CO}_{2}$ fixation and biofuel production via microalgae: Recent developments and future directions. Trends Biotechnol 28:371-380 . doi: 10.1016/j.tibtech.2010.04.004

Magdouli S, Brar SK, Blais JF (2016) Co-culture for lipid production: Advances and challenges. Biomass and Bioenergy 92:20-30 . doi: 10.1016/j.biombioe.2016.06.003

Milledge JJ, Heaven S (2013) A review of the harvesting of micro-algae for biofuel production. Rev Environ 
Sci Biotechnol 12:165-178 . doi: 10.1007/s11157-012-9301-z

Müller K (2001) Pharmaceutically relevant metabolites from lichens. Appl Microbiol Biotechnol 56:9-16 . doi: $10.1007 / \mathrm{s} 002530100684$

Otterstedt K, Larsson C, Bill RM, Ståhlberg A, Boles E, Hohmann S, Gustafsson L (2004) Switching the mode of metabolism in the yeast Saccharomyces cerevisiae. EMBO Rep 5:532-537 . doi: 10.1038/sj.embor.7400132

Oulhen N, Schulz BJ, Carrier TJ (2016) English translation of Heinrich Anton de Bary's 1878 speech, 'Die Erscheinung der Symbiose' ('De la symbiose'). Symbiosis 69:131-139 . doi: 10.1007/s13199-0160409-8

Patra M, Salonen E, Terama E, Vattulainen I, Faller R, Lee BW, Holopainen J, Karttunen M (2006) Under the influence of alcohol: The effect of ethanol and methanol on lipid bilayers. Biophys J 90:1121-1135 . doi: 10.1529/biophysj.105.062364

Peña A, Sánchez NS ilvi., Álvarez H, Calahorra M, Ramírez J (2015) Effects of high medium pH on growth, metabolism and transport in Saccharomyces cerevisiae. FEMS Yeast Res 15:1-13 . doi: 10.1093/femsyr/fou005

Pfaffinger CE, Schöne D, Trunz S, Löwe H, Weuster-Botz D (2016) Model-based optimization of microalgae areal productivity in flat-plate gas-lift photobioreactors. Algal Res 20:153-163 . doi: 10.1016/j.algal.2016.10.002

Pragya N, Pandey KK, Sahoo PK (2013) A review on harvesting, oil extraction and biofuels production technologies from microalgae. Renew Sustain Energy Rev 24:159-171 . doi: 10.1016/j.rser.2013.03.034

Puangbut M, Leesing R (2012) Integrated Cultivation Technique for Microbial Lipid Production by Photosynthetic Microalgae and Locally Oleaginous Yeast. World Acad Sci Eng Technol 6:975-979

Qin S, Moldaves K, S. McLaughlin C (1987) Isolation of the Yeast Gene Encoding Elongation Factor 3 for Protein Synthesis. J Biol Chem 262:7802-7807

Rai PK, Singh SP, Asthana RK (2012) Biohydrogen production from cheese whey wastewater in a two-step anaerobic process. Appl Biochem Biotechnol 167:1540-1549 . doi: 10.1007/s12010-011-9488-4

Santos CA, Caldeira ML, Lopes da Silva T, Novais JM, Reis A (2013) Enhanced lipidic algae biomass production using gas transfer from a fermentative Rhodosporidium toruloides culture to an autotrophic Chlorella protothecoides culture. Bioresour Technol 138:48-54 . doi: 10.1016/j.biortech.2013.03.135

Santos CA, Reis A (2014) Microalgal symbiosis in biotechnology. Appl Microbiol Biotechnol 98:5839-5846 . doi: 10.1007/s00253-014-5764-x

Scherholz ML, Curtis WR (2013) Achieving pH control in microalgal cultures through fed-batch addition of stoichiometrically-balanced growth media. BMC Biotechnol 13:39 . doi: 10.1186/1472-6750-13-39

Shu CH, Tsai CC, Chen KY, Liao WH, Huang HC (2013) Enhancing high quality oil accumulation and carbon dioxide fixation by a mixed culture of Chlorella sp. and Saccharomyces cerevisiae. J Taiwan 
Inst Chem Eng 44:936-942 . doi: 10.1016/j.jtice.2013.04.001

632 Subashchandrabose SR, Ramakrishnan B, Megharaj M, Venkateswarlu K, Naidu R (2011) Consortia of

633

634

635

636

637

638

639

640

641

642

643

644

645

646

647 cyanobacteria/microalgae and bacteria: Biotechnological potential. Biotechnol Adv 29:896-907 . doi: 10.1016/j.biotechadv.2011.07.009

Verduyn C, Postma E, Scheffers WA, van Dijken JP (1990) Physiology of Saccharomyces cerevisiae in Anaerobic Glucose-Limited Chemostat Cultures. J Gen Microbiol 136:395-403 . doi: $10.1099 / 00221287-136-3-395$

Verduyn C, Zomerdijk TPL, Dijken JP, Scheffers WA (1984) Continuous measurement of ethanol production by aerobic yeast suspensions with an enzyme electrode. Appl Microbiol Biotechnol 19:181-185 . doi: 10.1007/BF00256451

Xue F, Miao J, Zhang X, Tan T (2010) A new strategy for lipid production by mix cultivation of Spirulina platensis and Rhodotorula glutinis. Appl Biochem Biotechnol 160:498-503 . doi: 10.1007/s12010-0088376-Z

Zhang Z, Ji H, Gong G, Zhang X, Tan T (2014) Synergistic effects of oleaginous yeast Rhodotorula glutinis and microalga Chlorella vulgaris for enhancement of biomass and lipid yields. Bioresour Technol 164:93-99 . doi: 10.1016/j.biortech.2014.04.039 
Fig. 1 A coupled culture (a) and a mixed culture (b) of heterotrophic and autotrophic organisms; (a) gases pass from the liquid phase of the heterotrophic culture into a gaseous phase (blue dashed arrows) and they then pass from the gaseous phase into the liquid phase of the photo-bioreactor (red solid arrows); (b) Diagram of a mixed culture of heterotrophic and autotrophic organisms with $\mathrm{CO}_{2}$ produced by heterotrophic metabolism (the gases are generated and reused in situ)

Fig. 2 Flow chart for the development of a co-dominant mixed culture between S. cerevisiae and C. vulgaris

Fig. 3 Diagram showing the closed PBR configuration used for the mixed culture of microalgae and yeast. The culture was not aerated, and the bioreactor was fitted with a fermentation lock, by using a U-tube manometer filled with $200 \mathrm{~mm}$ of $\mathrm{H}_{2} \mathrm{O}$. The $\mathrm{pO}_{2}$ was monitored continuously using the immersed optic $\mathrm{pO}_{2}$ probe and the $\mathrm{pCO}_{2}$ sensors was placed in a loop that passed culture over it continuously by means of a peristaltic pump

Fig. 4 Validation of simultaneous enumeration of $C$. vulgaris and S. cerevisiae by flow cytometer; experimental versus reference ratios of $C$. vulgaris in eleven mixed cells suspensions (black circles) at different microalgae:yeast ratios

Fig. 5 Design of a specific medium for mixed culture; maximum population of S. cerevisiae GFP (light grey) or $C$. vulgaris (dark grey) in monoculture using three candidate media for mixed culture. Each monoculture of yeast or microalgae was performed in shake-flask and in duplicate

Fig. 6 S. cerevisiae monoculture in non-aerated PBR using heterotrophic MBM-GP medium. The yeast population is represented by orange circles. Glucose (filled triangles) and ethanol (empty triangles) are represented by symbols connected by dashed lines. Dissolved $\mathrm{O}_{2}$ is represented by blue solid line. Error bars represent standard deviations of duplicate analyses of population concentration

Fig. 7 C. vulgaris monoculture in aerated PBR using heterotrophic MBM-GP medium (a) and C. vulgaris monoculture in aerated PBR using autotrophic MBM medium (without glucose and peptone) (b). The microalgae population is represented by green squares. Dissolved $\mathrm{O}_{2}$ is represented by blue solid line and glucose (filled triangles) by symbols connected by dashed lines. Error bars represent standard deviations of duplicate analyses of population concentration

Fig. 8 Mixed culture No. 1 of $C$. vulgaris and S. cerevisiae in closed and non-aerated PBR using MBM-GP medium. The yeast inoculum was prepared using heterotrophic MBM-GP medium while the microalgae inoculum was prepared in autotrophic MBM medium. The yeast population is represented by orange circles and the microalgae population by green squares. Glucose (filled triangles) and ethanol (empty triangles) are represented by symbols connected by dashed lines. Dissolved $\mathrm{O}_{2}$ and $\mathrm{CO}_{2}$ are represented by blue dashed line and red solid line respectively. Error bars represent standard deviations of duplicate analyses

Fig. 9 Mixed culture No.2 of C. vulgaris and S. cerevisiae in closed and non-aerated PBR using MBM-GP medium. The yeast and microalgae inocula were both prepared in heterotrophic MBM-GP medium. The yeast population is represented by orange circles and the microalgae population by green squares. Glucose (filled triangles) and ethanol (empty triangles) are represented by symbols connected by dashed lines. Dissolved $\mathrm{O}_{2}$ is represented by blue solid line. Error bars represent standard deviations of duplicate analyses 
696 Fig. 10 Automatic addition of base $\mathrm{KOH}$ solution in S. cerevisiae monoculture and in mixed culture No. 2 for $697 \mathrm{pH}$ adjustment at 6.5 (a). Repartition of $\mathrm{CO}_{2}$ produced by S. cerevisiae in S. cerevisiae monoculture (b) and in 698 mixed culture No. 2 (c). Error bars represent standard deviations of duplicate analyses of yeast population

699 concentration

700 

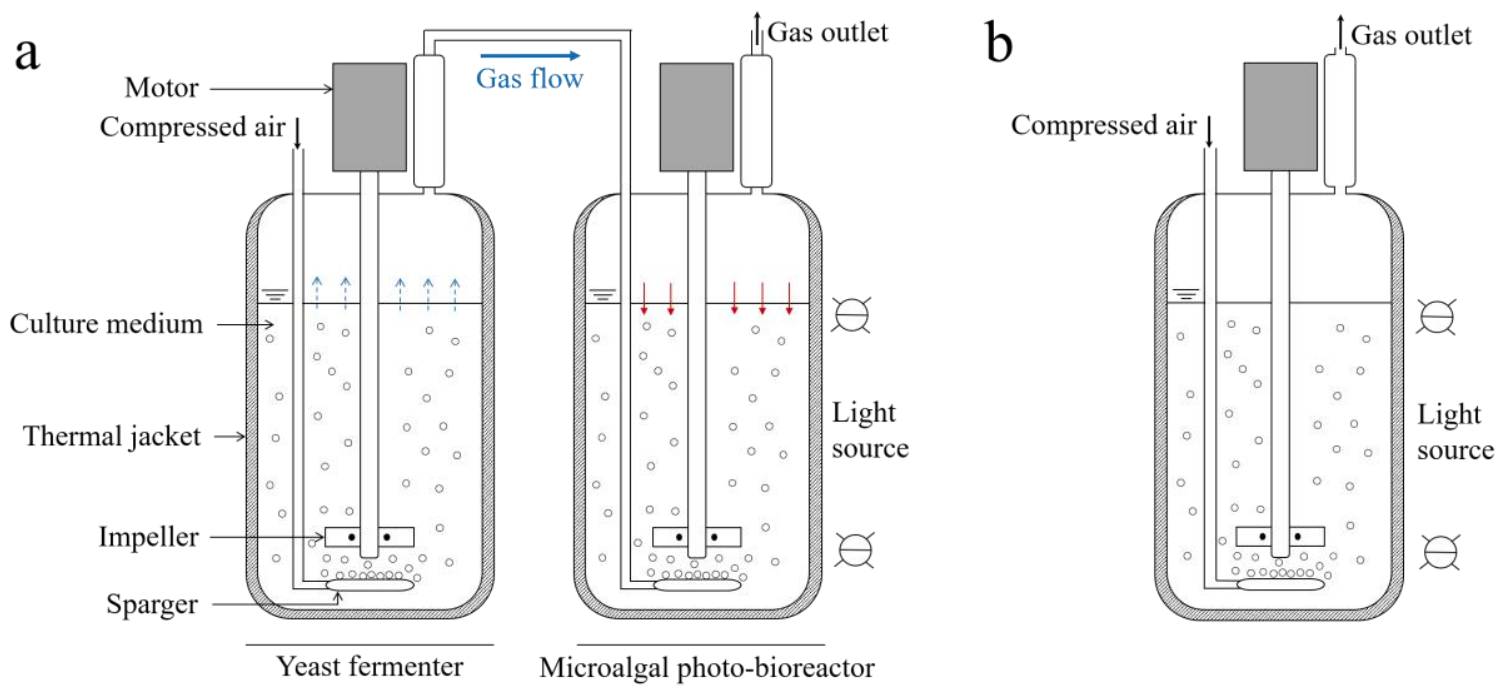

703

Fig. 1 program: PowerPoint 


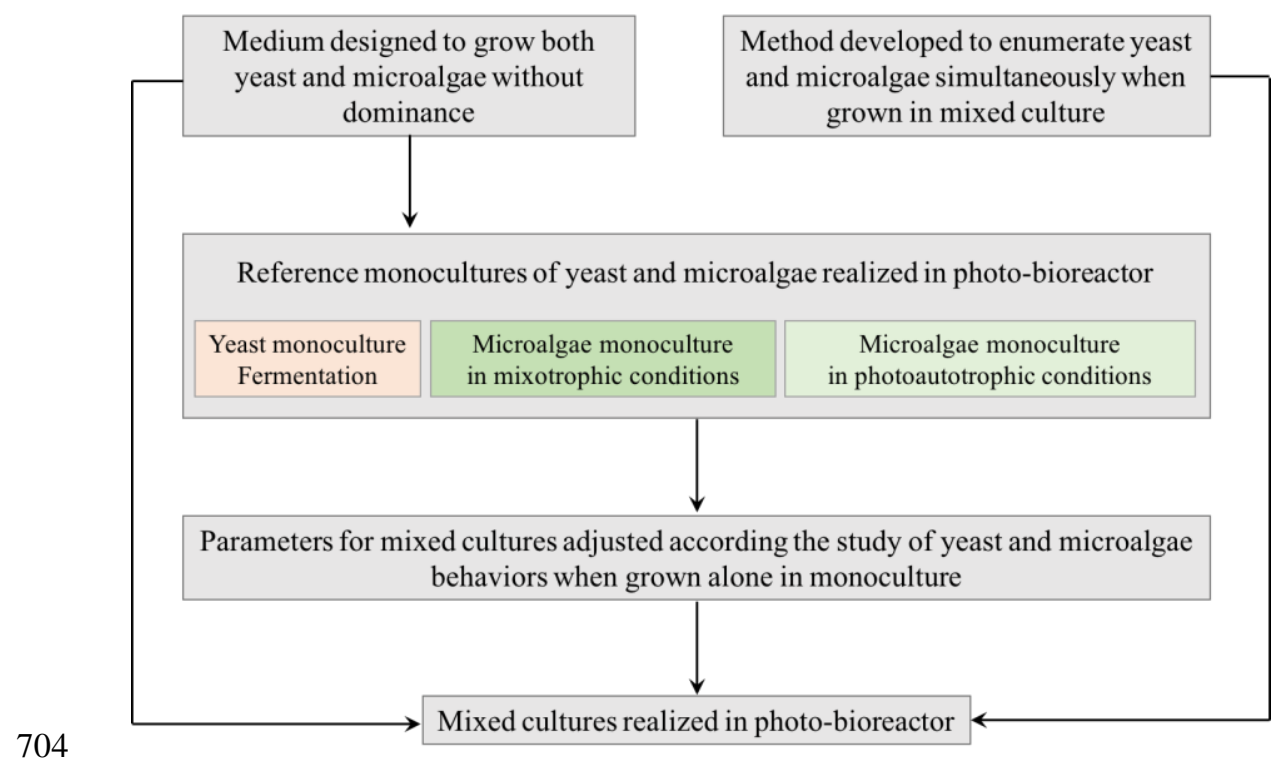

705 Fig. 2 program: PowerPoint 


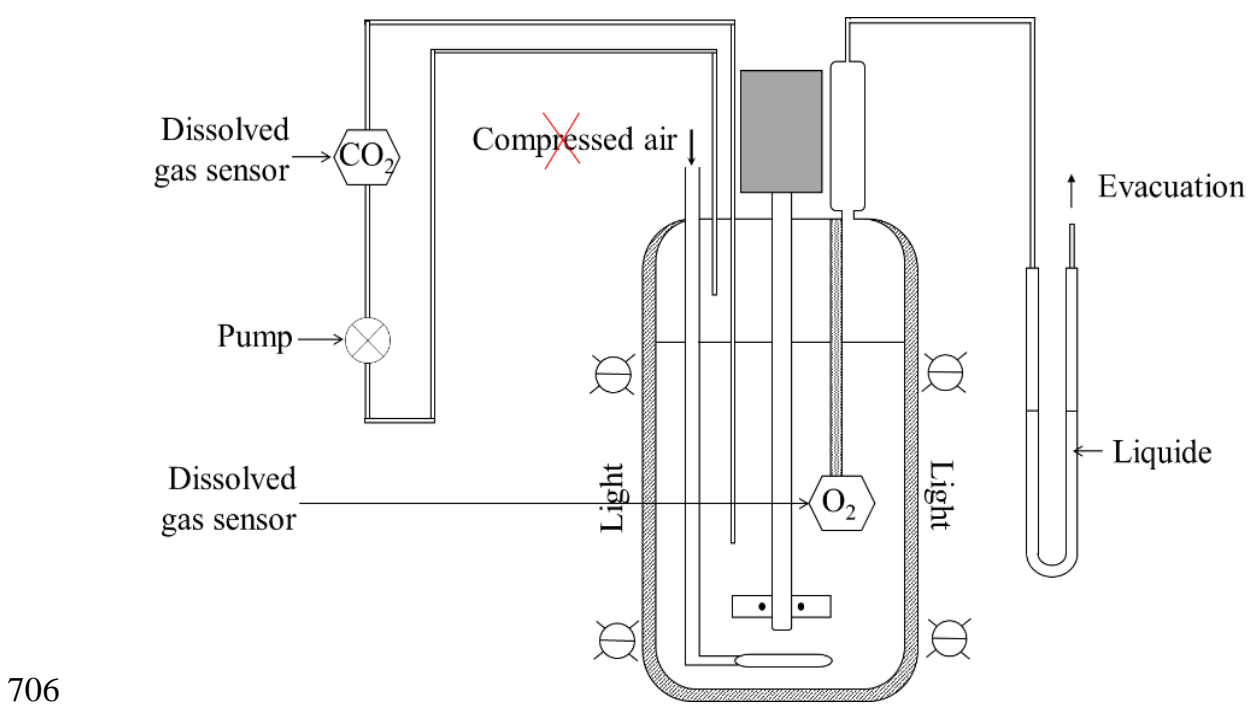

707

Fig. 3 program: PowerPoint 


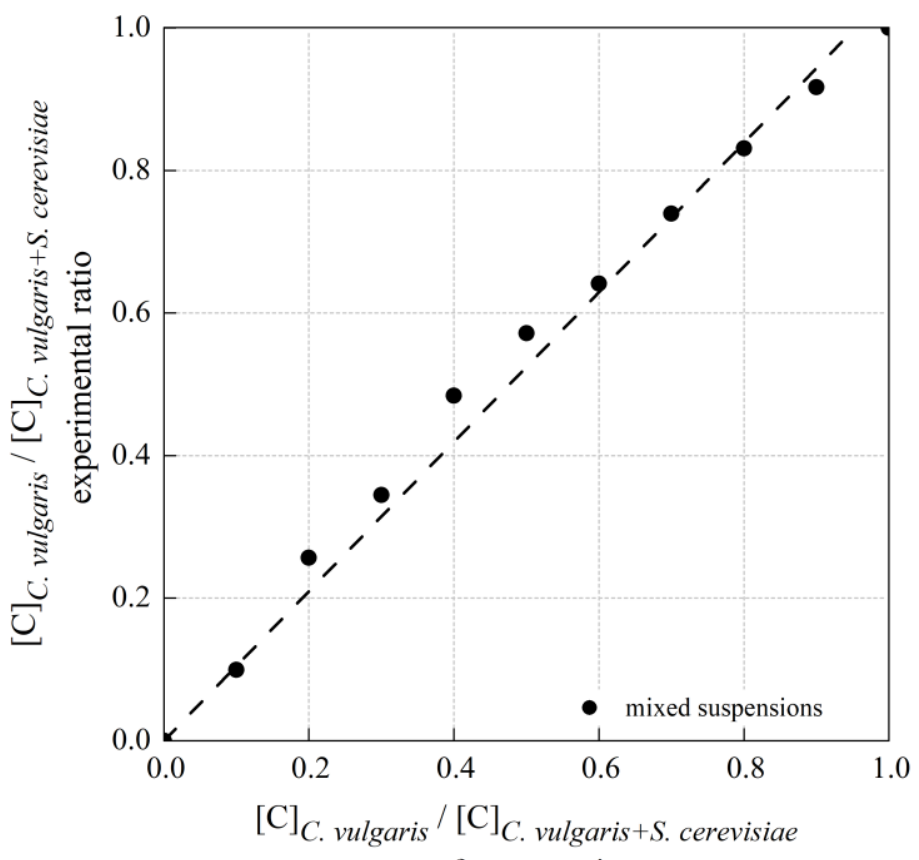

708 reference ratio

709 Fig. 4 program: OriginPro 


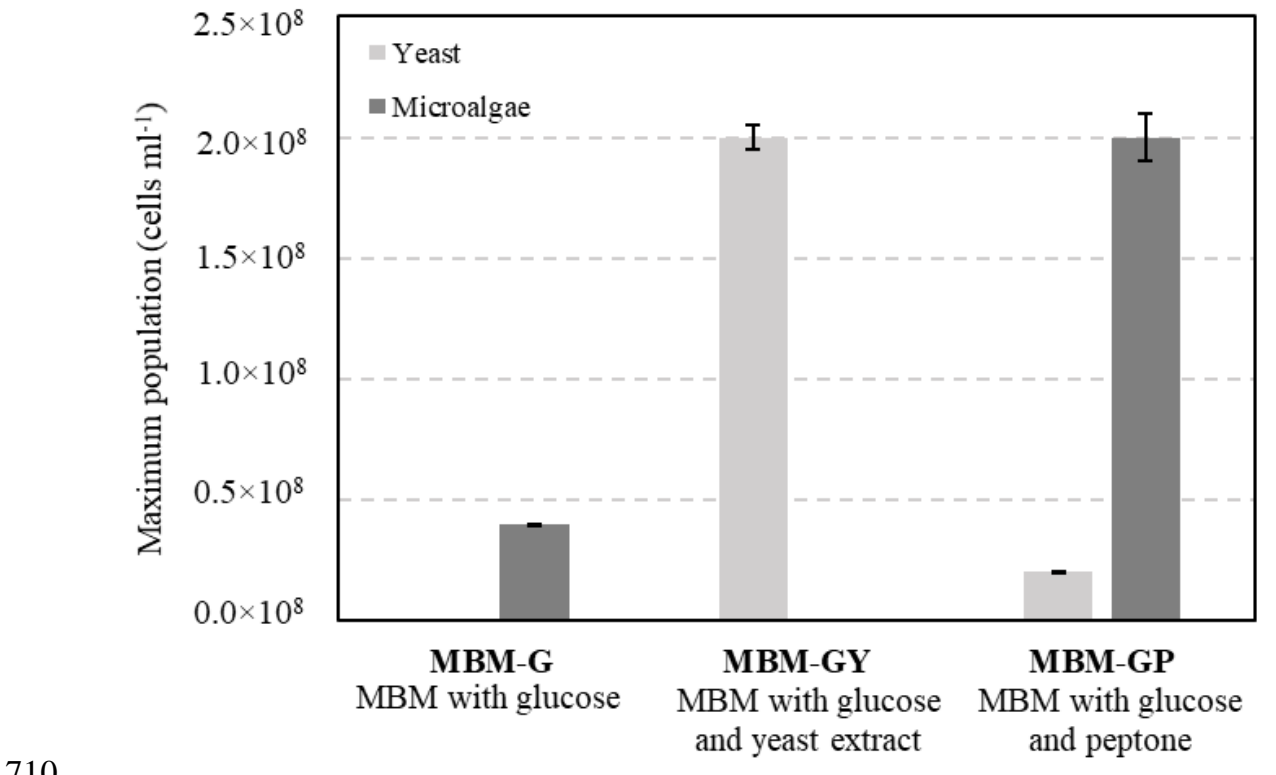

710

Fig. 5 program: OriginPro 


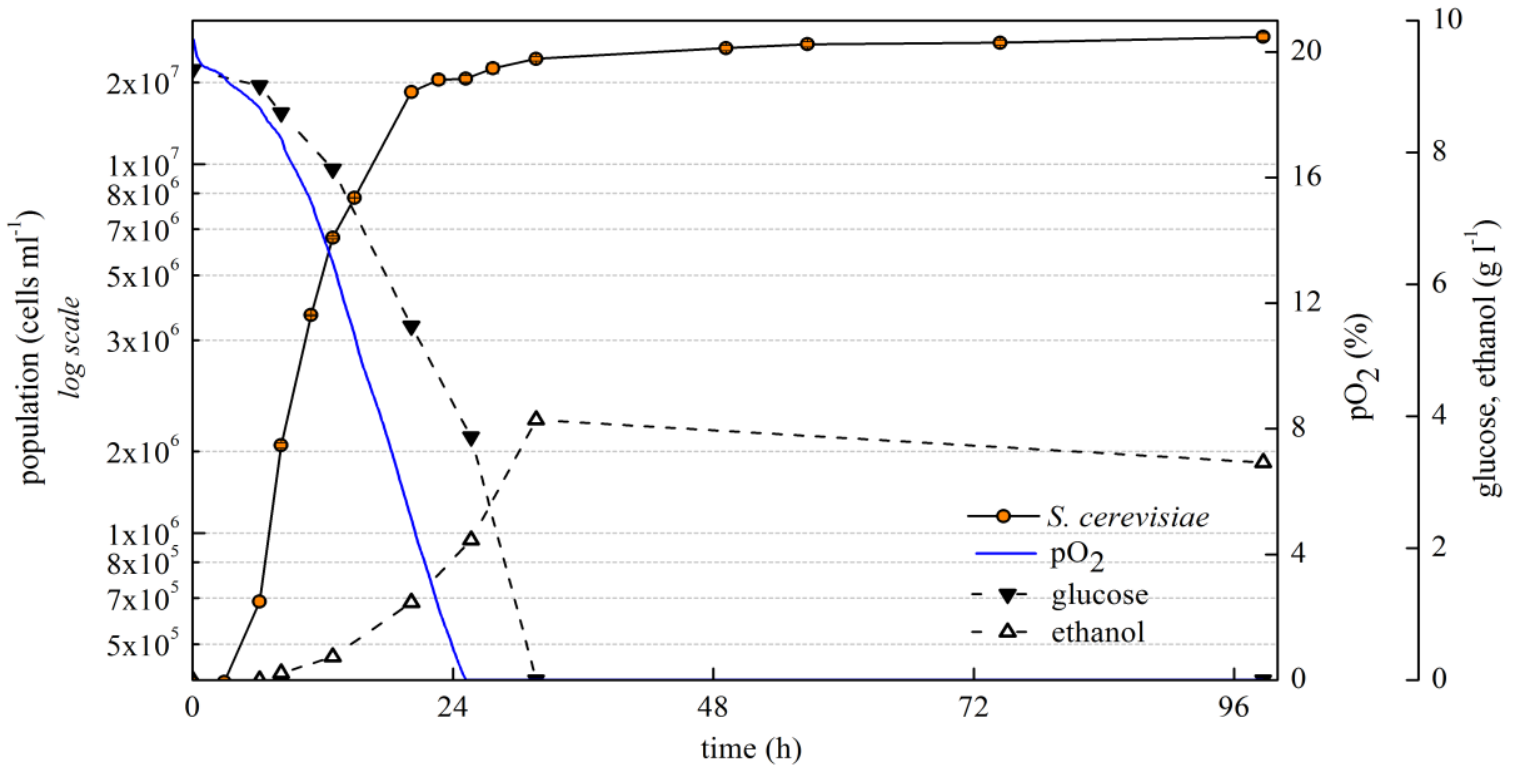

712

Fig. 6 program: OriginPro 

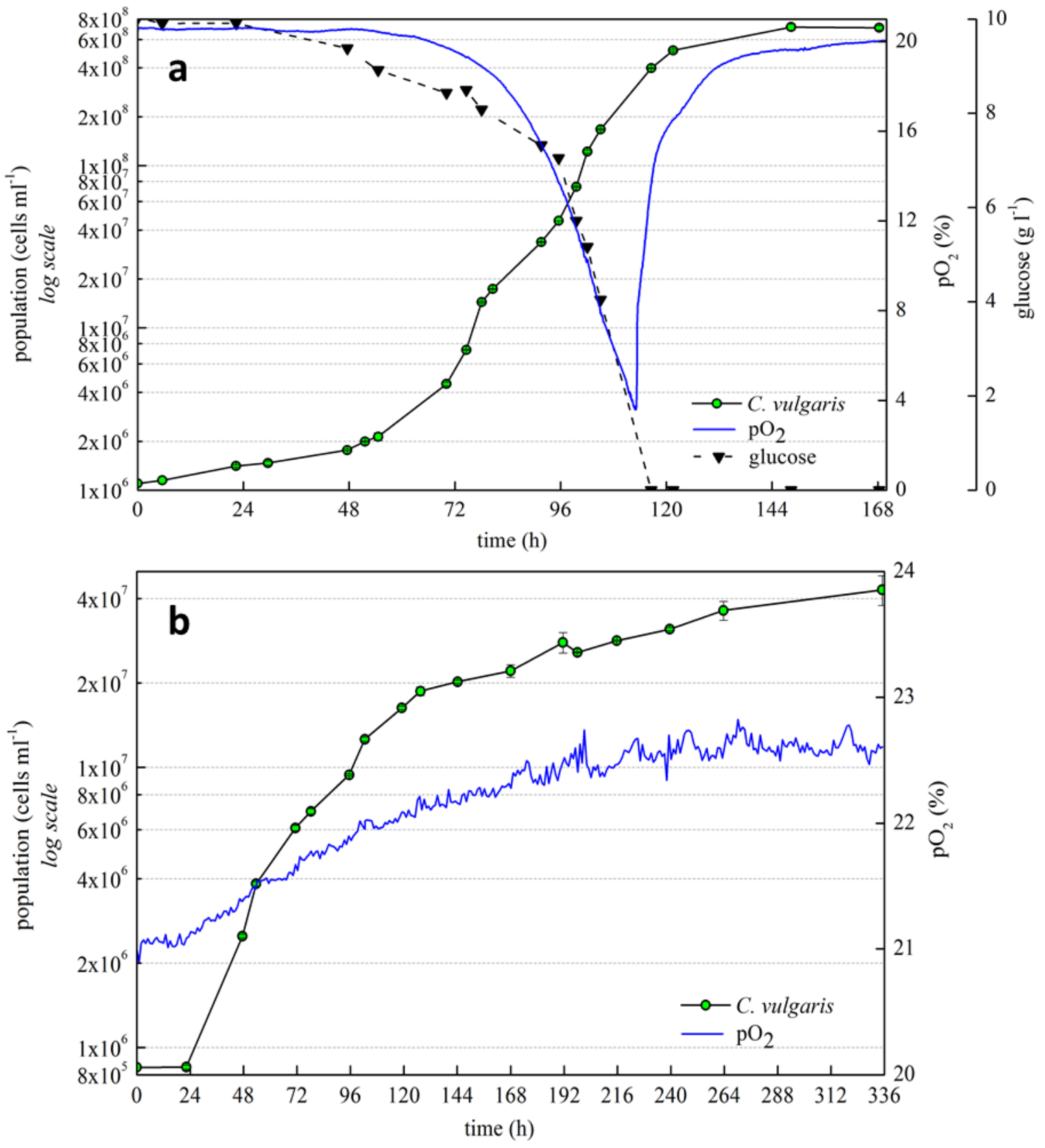

714

715

Fig. 7 program: OriginPro

716 


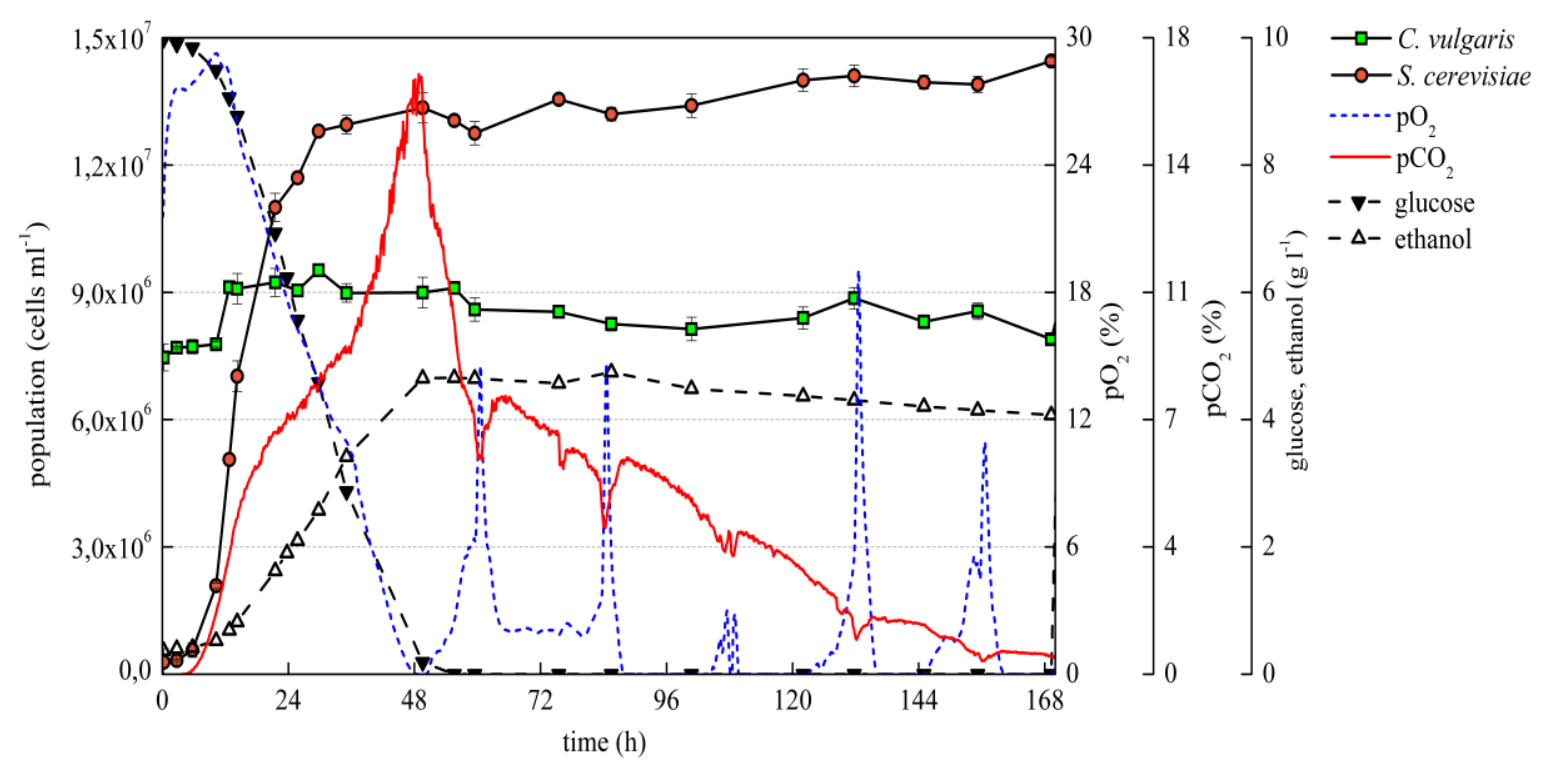

Fig. 8 program: OriginPro 


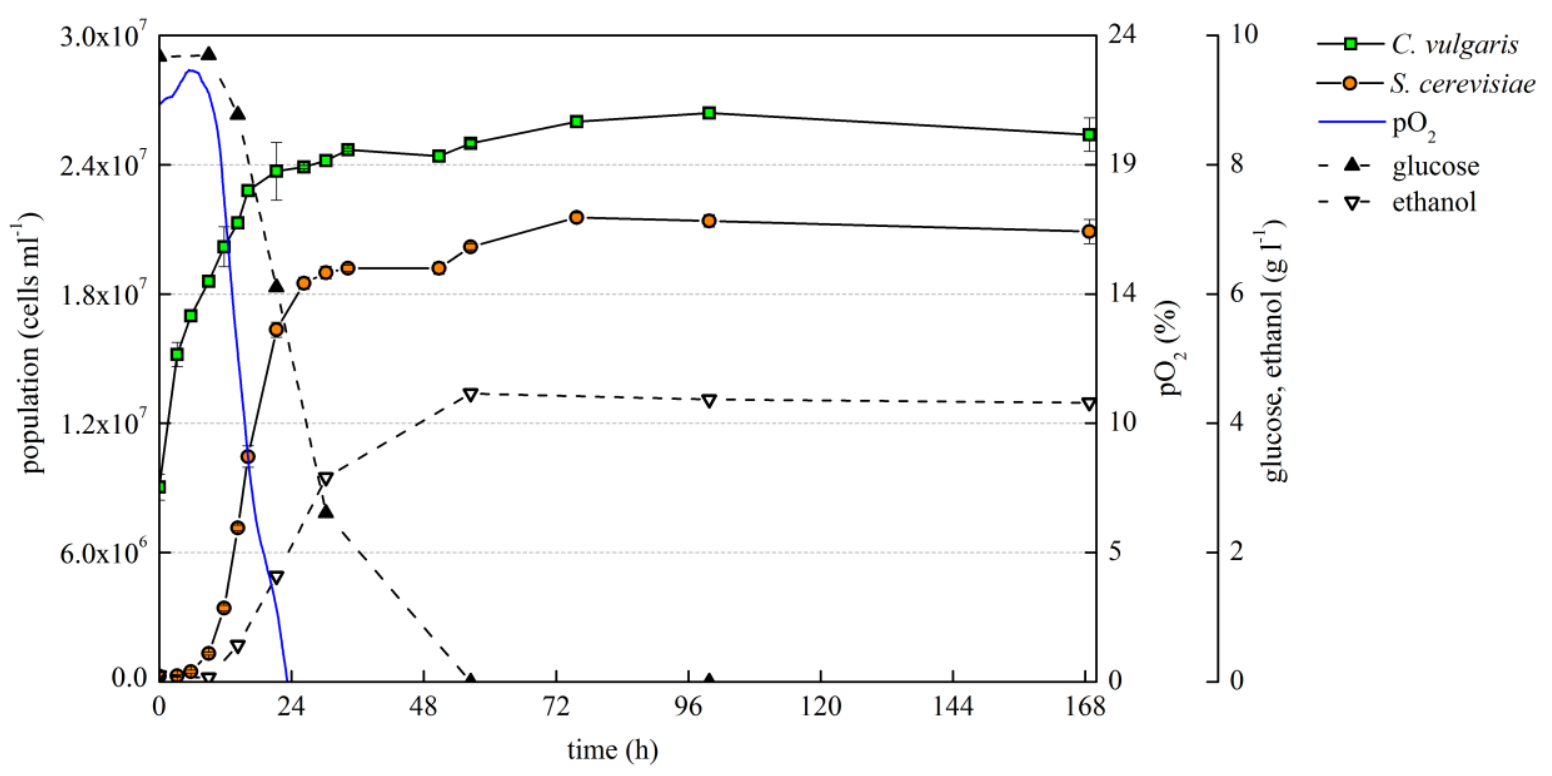

719

720

Fig. 9 program: OriginPro

721 


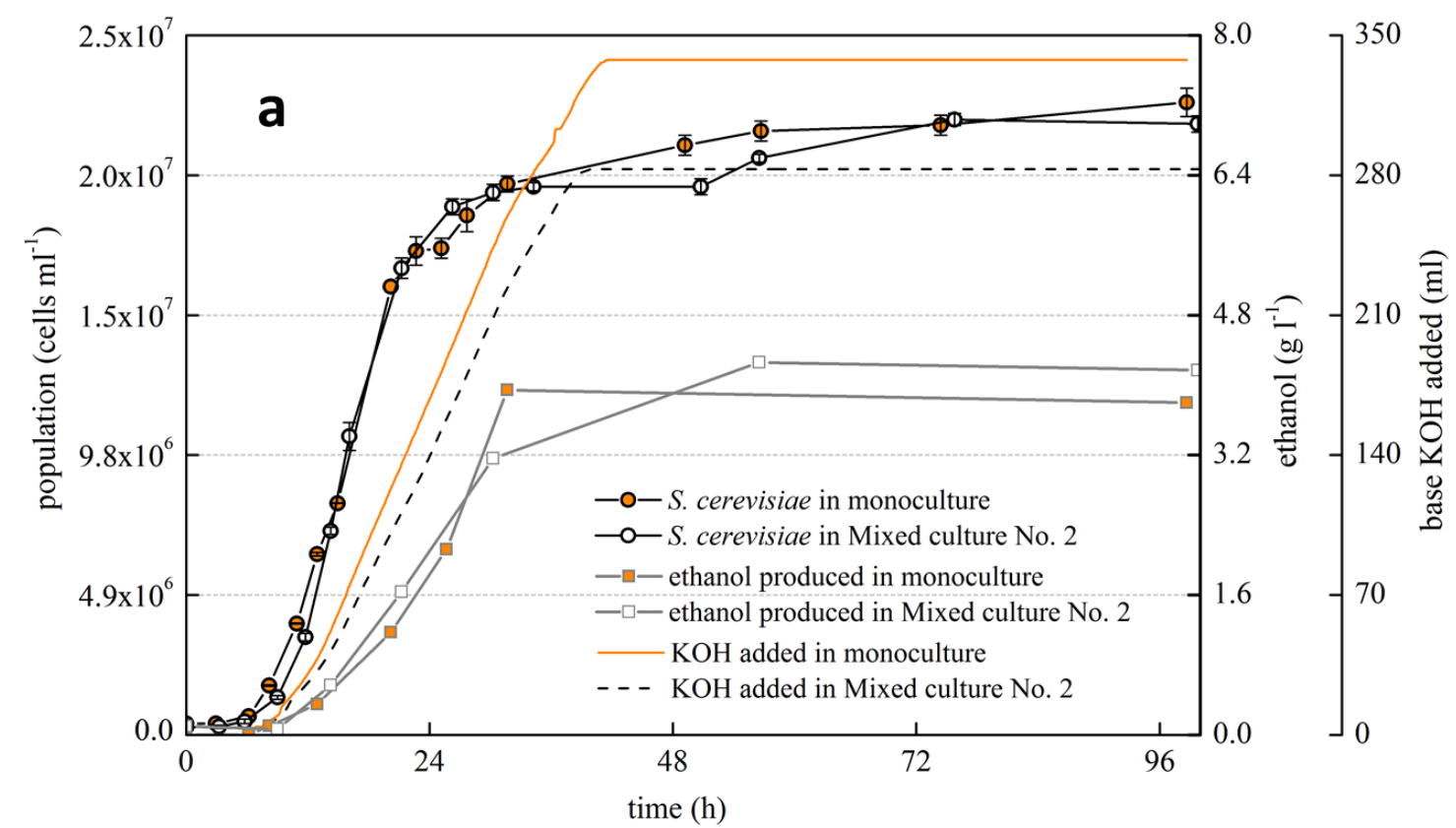

\section{b S. cerevisiae monoculture in PBR}

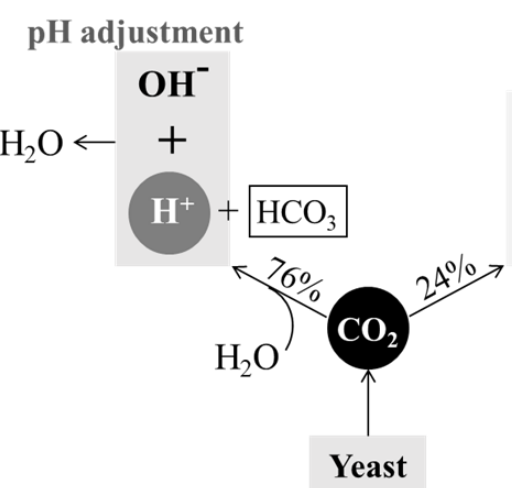

C Mixed culture No. 2 in PBR

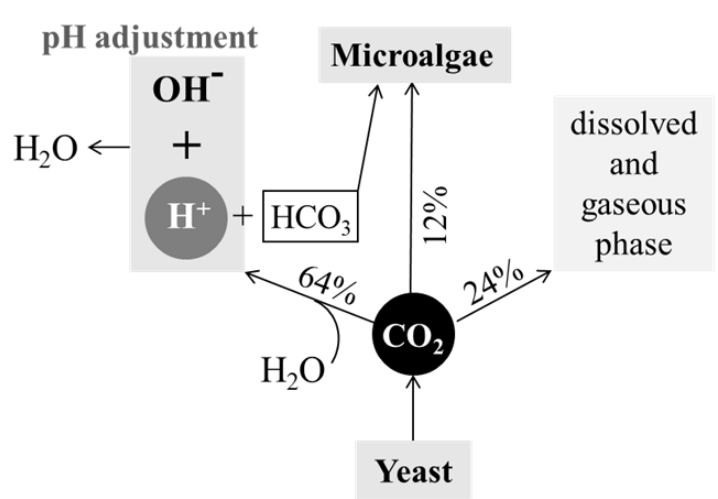

dissolved and gaseous phase

Fig. 10 program: OriginPro (a) and PowerPoint (b and c) 